\title{
Exploring Coping Effectiveness and Optimism among Municipal Employees
}

\author{
Tuija Muhonen $^{1}$, Eva Torkelson ${ }^{2}$ \\ ${ }^{1}$ Centre for Work Life Studies, Malmö University, Malmö, Sweden; \\ ${ }^{2}$ Department of Psychology, Lund University, Lund, Sweden. \\ Email: tuija.muhonen@mah.se \\ Received May $5^{\text {th }}, 2011$; revised July $15^{\text {th }}, 2011$; accepted August $19^{\text {th }}, 2011$.
}

\begin{abstract}
The aim of the study was to examine the relationship between coping, optimism, psychological and physical well-being. The effectiveness of the different coping strategies and the role of optimism were investigated by analyzing how they predicted psychological and physical well-being. Altogether 136 municipal employees participated in a questionnaire study. The results showed that the most adaptive or effective coping strategy concerning psychological and physical well-being was acceptance, which can be classified as engagement coping. Ineffective strategies regarding psychological well-being included disengagement coping strategies such as substance use, behavioral disengagement and self-blame. An ineffective strategy regarding physiological well-being was denial, which can be classified as a disengagement strategy. Optimism correlated significantly with both psychological and physical well-being. However, when all the variables in the model were included in the regression analysis, optimism explained additional variance in physical well-being but not in psychological well-being.
\end{abstract}

Keywords: Coping, Optimism, Well-Being

\section{Introduction}

Coping is considered as one of the most central concepts in stress research (Semmer \& Meier, 2009) and there is a growing body of studies investigating how people cope with stressful situations at work (cf. Carver, 1997; Tamres, Janicki \& Helgeson, 2002). Coping can be defined as cognitive and behaveioral efforts to manage different demands that tax or exceed a person's resources (Lazarus \& Folkman, 1984). There are several ways to categorize different coping strategies that people employ when facing stress (cf. Skinner, Edge, Altman \& Sherwood, 2003). One of the most common categorizations is to classify coping strategies as problem-focused or emotion-focused coping (Folkman \& Lazarus, 1980). The problem-focused coping strategies aim to modify or eliminate the source of stress, whereas emotion-focused strategies focus on adjusting emotional responses elicited by the stressful situation.

Although the distinction between emotion-focused and problem-focused strategies is widely acknowledged, it has been criticized as being conceptually too broad (Carver, Scheier \& Weintraub, 1989; Skinner et al., 2003) and confounding especially when it comes to emotion-focused coping, which includes divergent strategies (Farley, Galves, Dickinson \& Perez, 2005). Further, Carver and Connor-Smith (2010) point out that problem-focused and emotion-focused coping can be interrelated and that it is therefore more useful to consider them as complementary rather than distinct and independent categories. Some researchers distinguish instead between active coping, cognitive/emotional management, avoidant strategies and support seeking (Farley et al., 2005; Welbourne, Eggerth, Hartley, Andrew \& Sanchez, 2007).

Carver and Connor-Smith (2010) make a distinction between engagement coping and disengagement coping. Engagement coping aims to handle the stressor or emotions involved, whereas disengagement coping attempts to escape the stressor or emo- tions associated with it. Engagement coping then includes both problem-focused and emotion-focused strategies, e.g. support seeking, acceptance and cognitive restructuring (Carver \& Connor-Smith, 2010), whereas disengagement coping is focused on emotions with the aim of escaping feelings of distress, and includes strategies such as avoidance and denial.

According to Cunningham, De La Rosa and Jex (2008), effective coping "allows a person to maintain and possibly improve his/her well-being in the face of challenging (positive) or threatening (negative) situations" (p. 262). It is generally assumed to be more beneficial for well-being to actively cope with problems (Semmer \& Meier, 2009) than to use emotionfocused coping (Thoits, 1995). Some earlier studies have shown that problem-focused strategies are more beneficial for well-being (Bhagat, Allie, \& Ford, 1991), whereas emotionfocused strategies, are often considered to be positively associated with psychological distress (Coyne \& Racioppo, 2000). There are also studies (Torkelson \& Muhonen, 2003; 2004) that have not found any relationship between problem-focused strategies and health. These contradictory results indicate that no single coping strategy will be efficient across all situations (Thoits, 1995). Since coping effectiveness has so far received little attention in previous research (Pienaar, 2008) there is a need for further studies.

Personality characteristics such as optimism, i.e. an individual's generalized expectancy that future outcomes will be good (Scheier \& Carver, 1992), can influence how individuals cope with different demands related to work. People who are optimists have a propensity to use more problem-focused coping strategies, whereas pessimists are more prone to using denial or behavioral disengagement (Carver \& Scheier, 2005). Several studies have also found optimism to be beneficial for both psychological and physical well-being (Carver \& Scheier, 2005; Scheier \& Carver, 1992).

The aim of the present study was to examine the relationship between coping, optimism, psychological and physical well- 
being among a group of municipal employees. The effectiveness of the different coping strategies and the role of optimism were investigated by analyzing how they predicted psychologycal and physical well-being.

\section{Methods}

\section{Procedures}

Questionnaires were distributed to 230 municipal employees who visited a career coaching center in Western Sweden between March 2007 and March 2008. The career coaching center was established as a joint venture between eight municipalities in order to increase voluntary job mobility and thereby improve well-being among municipal employees who had permanent employment (a total of 17,000 employees). The staff turnover in general was low $(2 \%-4 \%)$, but according to earlier questionnaires conducted by the municipality $10 \%-20 \%$ of the employees wanted to change their jobs. The career coaching center aims to act proactively in order to increase job mobility to prevent the employees from developing ill-health.

\section{Participants}

All in all 136 questionnaires were returned by mail to the authors. The response rate was 59\%. The participants represented a broad spectrum of occupations, but the majority was working as teachers or nurses. A vast majority $(89 \%)$ of the participants were women, which could be anticipated due to the female dominance in the municipal sector in general. The mean age of the participants was 47 years $(\mathrm{SD}=8.7)$, and most of them were married $(77 \%)$. All of the participants had permanent employment in the municipality and had been working in their current occupation and current workplace for an average of nine years. A majority of the participants were not managers $(91 \%)$ and did not have university education (56\%). No gender differences concerning the background variables were found. A large proportion of the participants, $50 \%$, reported experiencing much or very much stress (Muhonen, 2010).

\section{Measures}

Demographics. The demographic questions included age, gender $(1=$ male, $2=$ female $)$, educational level $(1=$ university degree, $0=$ no university degree $)$, and organizational level $(1=$ manager, 2 = non-manager).

Coping. Coping was assessed by using the Swedish version of Brief COPE (Muhonen \& Torkelson, 2005) a scale originally developed by Carver (1997) consisting of 28 items that measure 14 different coping strategies, namely, self-distraction, active coping, denial, substance use, using emotional support, using instrumental support, behavioral disengagement, venting, positive reframing, planning, humor, acceptance, religion and selfblame. Brief COPE is widely used (Meyer, 2001; Welbourne et al., 2007) and has shown to have acceptable reliability (Carver, 1997; Muhonen \& Torkelson, 2005). The respondents rated each item on a 4-point scale from 1 (I haven't been doing this at all) to 4 (I've been doing this a lot) in order to indicate what they usually did when dealing with stress at work.

Optimism. Dispositional optimism was measured by the Swedish version (Muhonen \& Torkelson, 2005) of the Life Orientation Test-Revised (LOT-R). LOT was originally developed by Scheier and Carver (1992) and revised by Scheier, Carver and Bridges (1994). The LOT-R consists of six items that evaluate generalized expectancies for either positive or negative outcomes. A sample item is: "In uncertain times, I usually expect the best." Ratings were made on a 5-point scale from 1 (I agree a lot) to 5 (I disagree a lot). Higher scores on the LOT-R are considered to indicate increased optimism.

Psychological well-being. A Swedish version of the General Health Questionnaire-12 (Sconfienza, 1998), originally developed by Goldberg (1972) was used to assess psychological well-being. A sample item is: "I feel capable of making decisions." The respondents rated the items on a four-point scale from 0 (Disagree very much) to 3 (Agree very much). Responses were coded so that high values indicate low psychological well-being.

Physical well-being. Ten items from Subjective Health Complaints-SHC (Eriksen, Ihlebæk \& Ursin, 1999) were used to measure physical well-being. The participants indicated the severity of each complaint (e.g., headache, neck pain, dizziness) on a four-point scale from 0 (none) to 3 (severe).

Descriptive statistics and reliabilities for the study variables are presented in Table 1 . The Cronbach alpha values for the different coping strategies ranged from $\alpha=.88$ to $\alpha=.51$. The scales for optimism, psychological well-being and physical well-being also showed acceptable reliabilities $(\alpha=74-88)$.

Table 1.

Descriptive statistics and Cronbach's alphas for the study variables.

\begin{tabular}{|c|c|c|c|c|}
\hline & Variable & M & SD & $\alpha$ \\
\hline 1. & Age & 46.99 & 8.74 & n.a. \\
\hline 2. & Gender & 1.89 & .31 & n.a. \\
\hline 3. & Educational level & .44 & .50 & n.a. \\
\hline 4. & Position & 1.91 & .29 & n.a. \\
\hline 5. & Self-distraction & 2.23 & .72 & .56 \\
\hline 6. & Active coping & 3.13 & .57 & .70 \\
\hline 7. & Denial & 1.63 & .64 & .51 \\
\hline 8. & Substance use & 1.06 & .25 & .56 \\
\hline 9. & Using emotional support & 2.57 & .70 & .80 \\
\hline 10. & Using instrumental support & 2.58 & .65 & .75 \\
\hline 11. & Behavioral disengagement & 1.58 & .58 & .77 \\
\hline 12. & Venting & 2.46 & .67 & .68 \\
\hline 13. & Positive reframing & 2.71 & .63 & .67 \\
\hline 14. & Planning & 3.02 & .68 & .82 \\
\hline 15. & Humor & 2.17 & .74 & .88 \\
\hline 16. & Acceptance & 2.48 & .66 & .54 \\
\hline 17. & Religion & 1.49 & .77 & .87 \\
\hline 18. & Self-blame & 2.29 & .65 & .59 \\
\hline 19. & Psychological well-being & .98 & .56 & .88 \\
\hline 20. & Physical well-being & .57 & .50 & .82 \\
\hline 21. & Optimism & 3.38 & .74 & .74 \\
\hline
\end{tabular}

Note. $\mathrm{N}=130$ - 134. n.a. $=$ Not applicable. 


\section{Results}

\section{Coping and Well-Being}

As can be seen in Table 2, self-distraction, denial, behavioral disengagement and self-blame were coping strategies that were significantly correlated to poorer psychological as well as physical well-being. Active coping, emotional support, instrumenttal support, positive reframing, planning, humor and acceptance were correlated to better psychological well-being. None of the coping strategies was related to better physical well-being.

\section{Optimism, Coping and Well-Being}

Higher optimism was significantly related to active coping, emotional support, instrumental support, positive reframing and planning, whereas denial, behavioral disengagement and selfblame were related to lower optimism. Optimism was significantly related to educational level and position, indicating that participants who had a university education or a managerial position scored higher on optimism. Further, optimism correlated significantly with both psychological and physical wellbeing.

\section{Coping and Optimism as Predictors of Well-Being}

In order to investigate the role of the different coping strategies and optimism as predictors of psychological and physical well-being, separate multiple regression analyses were run on the data. Table 3 shows the results of hierarchical multiple regression analyses that were conducted in three steps. In the first step the demographic variables age, gender, educational level and position were entered as control variables. In the second step the coping strategies were entered in the analysis and finally in the third step the variable optimism was entered in the equation.

The results showed that none of the background variables predicted psychological or physical well-being. When it comes to coping, it was found that substance use, behavioral disengagement and self-blame were related to poorer psychological well-being, whereas acceptance was associated with better psychological well-being. Optimism did not contribute significantly to explained variance in psychological well-being. Only two of the coping strategies, namely denial and acceptance, acted as predictors of physical well-being. Denial was related to poorer physical well-being, whereas acceptance was related to

Table 2.

Correlations for the study variables.

\begin{tabular}{|c|c|c|c|c|c|c|c|c|c|c|c|c|c|c|c|c|c|c|c|c|c|}
\hline & Variable & 1 & 2 & 3 & 4 & 5 & 6 & 7 & 8 & 9 & 10 & 11 & 12 & 13 & 14 & 15 & 16 & 17 & 18 & 19 & 20 \\
\hline 1 & Age & - & & & & & & & & & & & & & & & & & & & \\
\hline 2 & Gender & -.18 & - & & & & & & & & & & & & & & & & & & \\
\hline 3 & Education & .03 & -.05 & - & & & & & & & & & & & & & & & & & \\
\hline 4 & Position & .09 & .10 & -.28 & - & & & & & & & & & & & & & & & & \\
\hline 5 & Self-distraction & .03 & -.02 & -.10 & -.01 & - & & & & & & & & & & & & & & & \\
\hline 6 & Active coping & .09 & -.12 & .32 & -.24 & -.10 & - & & & & & & & & & & & & & & \\
\hline 7 & Denial & .04 & .10 & -.47 & .15 & .28 & -.23 & - & & & & & & & & & & & & & \\
\hline 8 & Substance use & .10 & -.03 & .09 & -.03 & .01 & .16 & .08 & - & & & & & & & & & & & & \\
\hline 9 & Emot.support & .21 & .01 & -.03 & -.02 & .03 & .34 & .07 & .10 & - & & & & & & & & & & & \\
\hline 10 & Instr. support & .14 & .13 & .02 & -.08 & .09 & .34 & .09 & .03 & .75 & - & & & & & & & & & & \\
\hline 11 & Beh.disengagement & .06 & .09 & -.25 & .13 & .21 & -.39 & .40 & -.04 & -.20 & -.11 & - & & & & & & & & & \\
\hline 12 & Venting & .08 & .04 & .08 & .02 & .01 & .31 & .05 & .19 & .42 & .44 & -.02 & - & & & & & & & & \\
\hline 13 & Positive reframing & .01 & -.12 & .19 & -.10 & .08 & .41 & -.04 & .05 & .14 & .17 & -.27 & -.07 & - & & & & & & & \\
\hline 14 & Planning & .01 & -.12 & .21 & -.04 & .13 & .67 & -.09 & .15 & .28 & .32 & -.29 & .35 & .35 & - & & & & & & \\
\hline 15 & Humor & -.01 & .03 & .07 & .05 & .06 & .30 & .14 & .13 & .21 & .16 & -.06 & .13 & .24 & .37 & - & & & & & \\
\hline 16 & Acceptance & -.06 & -.12 & .11 & .06 & .05 & .23 & .01 & .05 & .19 & .09 & -.05 & .02 & .38 & .31 & .37 & - & & & & \\
\hline 17 & Religion & .05 & .05 & .12 & -.01 & .12 & -.10 & .05 & .02 & -.02 & .06 & .06 & -.08 & .20 & .02 & .14 & .13 & - & & & \\
\hline 18 & Self-blame & -.07 & .07 & .10 & .07 & .25 & .09 & .16 & .14 & .08 & .06 & .16 & .14 & .04 & .22 & .19 & .24 & .06 & - & & \\
\hline 19 & Psychol.well-being & .12 & .06 & -.05 & -.01 & .29 & -.33 & .26 & .12 & -.22 & -.19 & .51 & -.08 & -.28 & -.21 & -.21 & -.34 & .11 & .31 & - & \\
\hline 20 & Physical well-being & .02 & .07 & -.08 & -.02 & .31 & -.03 & .28 & .12 & .01 & -.06 & .18 & .17 & -.11 & .09 & .10 & -.11 & .06 & .28 & .49 & - \\
\hline 21 & Optimism & .11 & -.13 & .23 & -.20 & -.15 & .37 & -.23 & .03 & .29 & .28 & -.47 & .17 & .23 & .25 & .06 & -.06 & -.02 & -.21 & -.37 & -.21 \\
\hline
\end{tabular}

Note. Spearman's rho (listwise deletion of missing values). $\mathrm{N}=121$. Correlations $\geq .18$ are significant at the 0.05 level (two-tailed). Gender $(1=$ male; $2=$ female); educational level $(0=$ no university education; $1=$ university education); position $(1=$ manager; $2=$ non-manager $)$; psychological and physical well-being (higher values indicate poorer well-being); optimism (higher values indicate increased optimism). 
Table 3.

Results of hierarchical regression analyses predicting psychological well-being and physiological well-being.

\begin{tabular}{|c|c|c|c|c|c|c|}
\hline \multirow{2}{*}{ Variables } & \multicolumn{3}{|c|}{ Psychological well-being } & \multicolumn{3}{|c|}{ Physical well-being } \\
\hline & $\beta$ & $\Delta \mathrm{R}^{2}$ & $\mathrm{R}^{2}$ & $\beta$ & $\Delta \mathrm{R}^{2}$ & $\mathrm{R}^{2}$ \\
\hline Step 1 & & .01 & .01 & & .01 & .01 \\
\hline Age & .09 & & & .03 & & \\
\hline Gender & .03 & & & .03 & & \\
\hline Educational level & .14 & & & .06 & & \\
\hline Position & -.08 & & & -.08 & & \\
\hline Step 2 & & $.59^{* *}$ & .60 & & $.29 * *$ & .30 \\
\hline Self-distraction & .08 & & & .14 & & \\
\hline Active coping & -.08 & & & -.02 & & \\
\hline Denial & .11 & & & $.25^{*}$ & & \\
\hline Substance use & $.17^{*}$ & & & .04 & & \\
\hline Emotional support & .12 & & & .12 & & \\
\hline Instrumental support & -.14 & & & -.25 & & \\
\hline Beh. disengagement & $.37 * *$ & & & -.03 & & \\
\hline Venting & -.10 & & & .18 & & \\
\hline Positive reframing & -.02 & & & -.04 & & \\
\hline Planning & .12 & & & .10 & & \\
\hline Humor & -.13 & & & .09 & & \\
\hline Acceptance & $-.36^{* *}$ & & & $-.26^{*}$ & & \\
\hline Religion & .06 & & & .04 & & \\
\hline Self-blame & $.27^{* *}$ & & & .17 & & \\
\hline Step 3 & & .01 & .61 & & $.03 *$ & .33 \\
\hline Optimism & -.14 & & & $-.22 *$ & & \\
\hline
\end{tabular}

Note. $\mathrm{N}=121 . * p<.05, * * p<.01$.

better physical well-being. Further, optimism contributed to explained variance in physical well-being.

\section{Discussion}

In this study relationships between coping, optimism, psychological and physical well-being were investigated among a group of municipal employees. The role of optimism and the effectiveness of the different coping strategies were investigated by analyzing how they predicted psychological and physical well-being.

The results showed that the coping strategies self-distraction, denial, behavioral disengagement and self-blame were related to poorer psychological and physical well-being. All these strategies could be categorized as emotion-focused (Carver et al., 1989; Folkman \& Lazarus, 1980), but also as disengagement coping (Carver \& Connor-Smith, 2010). These findings are in line with earlier research indicating that the emotion-focused strategies are less beneficial (Coyne \& Racioppo, 2000) or effective. The correlations showed that none of the coping strate- gies was associated with better physical well-being, whereas several strategies, i.e. active coping, emotional support, instrumental support, positive reframing, planning, humor and acceptance, were related to better psychological well-being. These strategies could be classified as engagement coping (Carver \& Connor-Smith, 2010), and therefore in accordance with earlier research showing that disengagement coping is ineffective in reducing distress (Carver \& Connor-Smith, 2010).

The results showed that a higher level of optimism correlated significantly with active coping, emotional support, instrumenttal support, positive reframing and planning, whereas denial, behavioral disengagement and self-blame were related to lower optimism. This confirms earlier findings by Carver \& Scheier (2005) who found that optimists have a propensity to use more problem-focused coping strategies, whereas pessimists are more prone to use denial or behavioral disengagement.

Optimism also correlated significantly with both psychological and physical well-being, relationships that have also been found in earlier research (Carver \& Scheier, 2005; Scheier $\&$ Carver, 1992). Furthermore the results revealed that partici- 
pants who had university education or managerial position scored significantly higher on optimism, but optimism was not related to gender, which is in line with earlier studies (Muhonen \& Torkelson, 2005).

The results of the multiple regression analyses showed that none of the background variables predicted psychological or physical well-being. When it comes to coping, the results revealed a somewhat different pattern for psychological and physical well-being. Substance use, behavioral disengagement and self-blame were related to poorer psychological well-being, while acceptance was associated with better psychological well-being. Only two of the coping strategies, namely denial and acceptance, acted as predictors for physical well-being. Denial was related to poorer physical well-being, whereas acceptance was related to better physical well-being. The results of the study indicate that the most adaptive or effective coping strategy when it comes to both psychological and physical well-being was acceptance. The distinction between disengagement and engagement coping (Carver \& Connor-Smith, 2010) is supported by the results of the study. The coping strategies that predicted poorer psychological well-being, namely substance use, behavioral disengagement and self-blame, can be classified as disengagement coping, whereas the coping strategy acceptance, which predicted both psychological and physical well-being, can be classified as engagement coping (Carver $\&$ Connor-Smith, 2010). Disengagement coping in the form of denial appeared to be ineffective, whereas engagement coping in the form of acceptance seemed to be effective when it comes to psychological and physical well-being. In earlier studies both of these strategies have been categorized as emotion-focused coping despite the fact that these strategies can lead to different outcomes (Carver \& Scheier, 2005). Denial is a strategy that means refusing to face reality and attempting to rely on a view that is no longer relevant, whereas acceptance indicates restructuring the experiences in order to cope with the reality of the situation (Carver \& Scheier, 2005).

The relationship between optimism and well-being appeared to be somewhat inconclusive. Even though optimism correlated significantly with both psychological and physical well-being, it only predicted physical but not psychological well-being when all the other variables in the model were controlled for. This is a somewhat puzzling finding that needs to be investigated further.

There are some limitations in this study that should be taken into consideration. The number of participants is rather limited, consisting of employees who represent a broad range of occupations in the municipal sector. Some of the alpha values for the coping scales, e.g. acceptance, denial, were somewhat low. Since the reliability coefficient is related to the number of items per scale (Cortina, 1993), it can be difficult to attain high reliability values for scales that only consists of two items, as in Brief COPE. And finally, since this a cross-sectional study, no causal conclusions can be drawn.

In sum, the results of the study support the classification of coping strategies into disengagement and engagement coping, rather than using the emotion-focused and problem-focused distinction. The most adaptive or effective coping strategy concerning psychological and physical well-being was acceptance, which can be classified as engagement coping. Ineffective strategies regarding psychological well-being included disengagement coping strategies such as substance use, behavioral disengagement and self-blame. An ineffective strategy regarding physiological well-being was denial, which can be classified as a disengagement strategy. Optimism correlated significantly with both psychological and physical well-being. However, when all the variables in the model were included in the regression analysis, optimism explained additional variance in physical well-being but not in psychological wellbeing.

Considering the high rate of stress in current working life, it is important to investigate further the effectiveness of disengagement and engagement coping in order to be able to strengthen coping capacity among employees.

\section{References}

Bhagat, R. S., Allie, S. M., \& Ford, D. L. Jr. (1991). Organizational stress, personal life stress and symptoms of life strain: An inquiry into the moderating role of styles of coping. Journal of Social Behavior and Personality, 6, 163-184.

Carver, C. S. (1997). You want to measure coping but your protocol's too long: Consider the Brief COPE. International Journal of Behavioral Medicine, 4, 92-100. doi:10.1207/s15327558ijbm0401 6

Carver, C. S., \& Connor-Smith, J. (2010). Personality and coping. Annual Review of Psychology, 61, 679-704. doi:10.1146/annurev.psych.093008.100352

Carver, C. S., \& Scheier, M. F. (2005). Optimism. In C. R. Snyder and S. J. Lopez, (Eds.) Handbook of positive psychology (pp. 231-243) New York: Oxford University Press.

Carver, C. S., Scheier, M. F., \& Weintraub, J. K. (1989). Assessing coping strategies: A theoretically based approach. Journal of Personality and Social Psychology, 56, 267-283. doi:10.1037/0022-3514.56.2.267

Cortina, J. M. (1993). What is coefficient alpha? An examination of theory and applications. Journal of Applied Psychology, 78, 98-104. doi:10.1037/0021-9010.78.1.98

Coyne, J. C., \& Racioppo, M. W. (2000). Never the twain shall meet? Closing the gap between coping research and clinical intervention research. American Psychologist, 55, 655-664. doi:10.1037/0003-066X.55.6.655

Cunningham, J. L., De La Rosa, G. M., \& Jex, S. M. (2008). The dynamic influence of individual characteristics on employees well-being: a review of theory, research and future directions. In K. Näswall, J. Hellgren and M. Sverke (Eds.), The individual in the changing working life (pp. 258-283). Cambridge: Cambridge University Press.

Eriksen, H. R., Ihlebæk C., \& Ursin, H. (1999). A scoring system for subjective health complaints (SCH). Scandinavian Journal of Public Health, 1, 63-72. doi:10.1177/14034948990270010401

Farley, T., Galves, A., Dickinson, M., \& Perez, M. J. D. (2005). Stress, coping, and health. A comparison of Mexican immigrants, MexicanAmericans, and Non-Hispanic Whites. Journal of Immigrant Health, 7, 213-220. doi:10.1007/s10903-005-3678-5

Folkman, S., \& Lazarus, R. S. (1980). An analysis of coping in middle-aged community sample. Journal of Health and Social Behavior, 21, 219-239. doi:10.2307/2136617

Goldberg, D. P. (1972). The detection of psychiatric illness by questionnaire. Oxford: Oxford University Press.

Lazarus, R. S., \& Folkman, S. (1984). Stress, appraisal, and coping. New York: Springer Publishing Company.

Meyer, B. (2001). Coping with severe mental illness: Relations of the Brief COPE with symptoms, functioning and well-being. Journal of Psychopathology and Behavioral Assessment, 23, 265-277. doi:10.1023/A:1012731520781

Muhonen, T. (2010). Feeling double locked-in at work-implications for health and job satisfaction among municipal employees. WORK, 36

Muhonen, T., \& Torkelson, E. (2005). Kortversioner av frågeformulär inom arbets-och hälsopsykologi-om att mäta coping och optimism. Nordisk Psykologi, 57, 288-297.

Pienaar, J. (2008). Skeleton key or siren song: is coping the answer to balancing work and well-being? In K. Näswall, J. Hellgren and M. Sverke (Eds.), The individual in the changing working life (pp. 235-257). Cambridge: Cambridge University Press.

Sconfienza, C. (1998). Mätning av psykiskt välbefinnande bland ungdomar i Sverige. Användning av GHQ-12. [Measuring mental 
health among young people in Sweden. The use of GHQ-12]. Arbete och Hälsa, 22, 1-35.

Scheier, M. F., \& Carver, C. S. (1992). Effects of optimism on psychological and physical well-being: Theoretical overview and empirical update. Cognitive Therapy and Research, 16, 201-228. doi:10.1007/BF01173489

Scheier, M. F., Carver, C. S., \& Bridges, M. W. (1994). Distinguishing optimism from neuroticism (and trait anxiety, self-mastery, and self-esteem): A re-evaluation of the Life Orientation Test. Journal of Personality and Social Psychology, 67, 1063-1078. doi:10.1037/0022-3514.67.6.1063

Semmer, N. K., \& Meier, L. L. (2009). Individual differences, work stress and health. In C. L. Cooper, J. Campbell and M. J. Schabracq (Eds.), International handbook of work and health psychology (pp. 99-121). Chichester: John Wiley \& Sons Ltd.

doi:10.1002/9780470682357.ch6

Skinner, E. A., Edge, K., Altman, J., \& Sherwood, H. (2003). Searching for the structure of coping: A review and critique of category systems for classifying ways of coping. Psychological Bulletin, 19, 216-269. doi:10.1037/0033-2909.129.2.216

Tamres, L. K., Janicki, D., \& Helgeson, V. S. (2002). Sex differences in coping behavior: A meta-analytic review and an examination of relative coping. Journal of Personality and Social Psychology Review, 6 , 2-30. doi:10.1207/S15327957PSPR0601 1

Thoits, P. A. (1995). Stress, coping, and social support processes: Where are we? What next? Journal of Health and Social Behavior, 35, 53-79. doi: $10.2307 / 2626957$

Torkelson, E., \& Muhonen, T. (2003). Coping strategies and health symptoms among women and men in a downsizing organisation. Psychological Reports, 92, 899-907.

Welbourne, J. L., Eggerth, D., Hartley, T. A., Andrew, M. E., \& Sanchez, F. (2007). Coping strategies in the workplace: Relationships with attributional style and job satisfaction. Journal of Vocational Behavior, 70, 312-325. doi:10.1016/j.jvb.2006.10.006 